ENCYCLOPEDDE Encyclopédie berbère

BERBERE

$2 \mid 1985$

2 | Ad - Ağuh-n-Tahlé

\title{
Africa
}

\section{W. Vycichl}

\section{OpenEdition}

Journals

Édition électronique

URL : http://journals.openedition.org/encyclopedieberbere/888

DOI : $10.4000 /$ encyclopedieberbere.888

ISSN : 2262-7197

\section{Éditeur}

Peeters Publishers

\section{Édition imprimée}

Date de publication : 1 novembre 1985

Pagination : 216-217

ISBN : 2-85744-209-2

ISSN : 1015-7344

\section{Référence électronique}

W. Vycichl, «Africa », Encyclopédie berbère [En ligne], 2 | 1985, document A79, mis en ligne le 01 décembre 2012, consulté le 25 septembre 2020. URL : http://journals.openedition.org/ encyclopedieberbere/888; DOI : https://doi.org/10.4000/encyclopedieberbere.888

Ce document a été généré automatiquement le 25 septembre 2020

(c) Tous droits réservés 


\section{Africa}

\section{W. Vycichl}

1 Pour les Romains, Africa désignait tout d'abord le territoire soumis à la domination carthaginoise transformé après la prise de Carthage (146 avant J.-C.) en province romaine. Cette ancienne provincia Africa correspondait à peu près au nord-est de la Tunisie actuelle, de Thabraca (Tabarca) jusqu'à Thaenae (Thyna, $11 \mathrm{~km}$ au sud de Sfax) au golfe de Gabès.

2 Après la défaite de Juba $\mathrm{I}^{\mathrm{er}}$ à Thapsus (46 avant J.-C.) la majeure partie de son royaume, la Numidie, fut annexée comme Africa nova pour la distinguer de l'ancienne province appelée Africa vetus. Les deux parties formèrent l'Afrique proconsulaire.

Sous Dioclétien (284-305) l'Afrique formait un diocèse comprenant les provinces de Tripolitania, Byzacena, Proconsularis ou Zeugitana, Numidia milita-ris, Numidia cirtensis, Mauretania Sitifensis et Mauretania Caesarensis. Le Nord-Ouest marocain, Mauretania Tingitana, faisait partie du diocèse d'Espagne.

3 L'Afrique prise au sens large que les Grecs appelaient la Libye (Pline l'Ancien, V 1), à savoir la partie de l'Afrique délimitée par le Nil, la Méditerranée et l'Atlantique (Pomponius Mela 1,4) constituait une des trois parties du monde des Anciens.

Ce n'est que plus tard, à l'époque des découvertes, que le nom d'Afrique fut étendu à tout le continent.

4 Etymologie. La désignation latine (Africa) signifie primitivement la terre des Afri, peuplade indigène du nord de la Tunisie actuelle, souvent confondue avec les Carthaginois, mais Tite-Live distingue bien les Afri des Carthaginois :

- « Hasdrubal plaça les Carthaginois à l'aile droite et les Afri à l'aile gauche » (XXIII 29, 4);

- « les Carthaginois et les vétérans Africains » (XXIII 28, 14);

- «les Carthaginois avaient comme mercenaires des Afri et des Numides» (XXIII 28, 44) ;

- "les cavaliers des Libyphoeniciens, une peuplade carthaginoise mélangée d'Afri» (XXIII 21, 22).

5 Frontin rapporte également que Maharbal avait été envoyé par les Carthaginois «pour réprimer une rébellion des Afri» (Strat. II 5, 12). Afer (subst. et adj.) a plusieurs 
significations :

A. adj. "relatif à l'Afrique, d'Afrique, africain», par ex. absinthum "absinthe", ammoniacum "gomme ammoniaque», avis "pintade», bitumen «bitume», bulbi "bulbes», cyminum «cumin»,ficum «figue», fucus «fucus, orseille», murex " coquillage dont on tirait la pourpre», oleum "huile», opopanax "opopanax", serpentes "serpents", spongia " éponge », sulphur "soufre", tapetia " tapis ", tunicae « tuniques », vinum « vin ». L'expression afer turbo existe comme expression poétique et correspond à africus ventus « vent de sud-ouest ».

B. subst. "habitant l'Afrique du Nord (sauf l'Égypte)", à savoir (1) Carthaginois, Punique ", (2) au pl. les "Carthaginois et leurs alliés africains", (3) les "Africains, auxiliaires ou ennemis des Carthaginois ».

C. subst. "Africain» comme cognomen latin, comp. Publius Terentius Afer (poète comique, né à Carthage) et $C$. Domitius Afer (orateur). Le cognomen Africanus désigne $P$. Cornelius Scipio Africanus (major), vainqueur de Zama (202 avant J.-C.) et P. Cornélius Scipio Aemilianus Africanus (minor) qui détruisit Carthage (146 avant J.-C).

Il est donc hors de doute que les Afri étaient une peuplade distincte des Carthaginois. La forme primitive de cette désignation était certainement $A f r{ }^{*}$ (au singulier) considérée par les Romains comme génitif du singulier (« de l’Afrī ») ou nominatif du pluriel (« les Afrīs »). La forme Afer est une forme «refaite» comme Poenus "Carthaginois » est

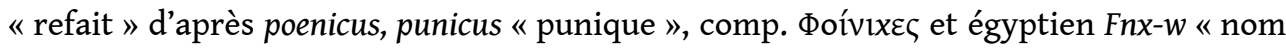
d'un peuple syro-palestinien » (A. Erman und H. Grapow, Wörterbuch der ägyptischen Sprache, vol. I, Leipzig 1926, p. 577).

7 On peut s'étonner que la forme Afrī ne présente pas la métaphonie, phénomène fréquent dans l'ancienne Tunisie, comparer les noms de lieu Thibilis, Thigibba, Thignica, Thimida, Thimisua, etc. On s'attendrait plutôt à *Ifrì.

8 Or, les formes sans et avec métaphonie sont assez irrégulièrement réparties. Nous donnons, à titre d'exemple plusieurs formes de noms en berbère des Beni Snous et en kabyle : aүil (BSn), iүil (Zw) «bras», afer (BSn), ifer (Zw) «aile», asli (BSn), isli (Zw) " fiancé, jeune marié », etc. (BSn = Beni Snous; $\mathrm{Zw}=\mathrm{Zwawa}$, kabyle) (E. Destaing, Etude sur le dialecte des Beni Snous, vol. I, Paris 1907, p. 53). D'ailleurs, la forme ifrì existe peutêtre comme nom de l'ancêtre des Banū İfran qui constituent la branche la plus considérable de la grande tribu des Zenāta (Tadeusz Lewicki, Banū Īfran. Encyclopédie de l'Islam. Nouvelle édition. Tome III. Leyde et Paris 1971, p. 1065-1070).

9 La tribu des Banū İfran était considérée comme les descendants d'İfrī, fils d'Islitan, fils de Misrā, fils de Zākiya, fils de Warsīk (ou Waršì) fils d'Adīdat, fils de Djāna, ancêtre éponyme de toutes les tribus zenatiennes.

Quant à Africus ou Africus ventus "vent du sud-ouest », vent qui amène la pluie, c'est bien le vent provenant d'Afrique. Ce n'est pas l'Afrique qui a reçu son nom du vent, mais le contraire.

10 En grec 'A рөхй, désigne primitivement la province romaine d'Afrique (distincte de la région géographique du même nom que les Grecs appelaient $\Lambda \mathrm{\imath} ß u ́ n \mid$ ) (A. Bailly, Dictionnaire latin-français. Paris, 1950, p. 330). 'A $\varphi$ pıx́́ est la transcription du latin Africa. L'arabe connaît deux formes, 'Ifrììiya $t$ et 'Ifrìqiyā (M. Talbi, Ifrīqiyā. Encyclopédie de l'Islam. Nouvelle Edition. Paris, 1971. III, p. 1073-1076). Cet article réunit également les étymologies mythologiques des Grecs et les essais d'explication des auteurs arabes. 
INDEX

Mots-clés : Romain, Etymologie 